\title{
Determination of selected phthalates by gas chromatography-mass spectrometry in mural paintings from Palermo (Italy)
}

\author{
Santino Orecchio *, Roberta Indelicato, Salvatore Barreca \\ Dipartimento di Scienze e Tecnologie Biologiche, Chimiche e Farmaceutiche, Università di Palermo, Viale delle Scienze, I-90128 Palermo, Italy
}

\section{A R T I C L E I N F O}

\section{Article history:}

Received 22 November 2013

Received in revised form 26 November 2013

Accepted 26 November 2013

Available online 4 December 2013

\section{Keywords:}

Mural paintings

Phthalates

GC-MS

Restore

Construction

\begin{abstract}
A B S T R A C T
Phthalate esters for decades, and probably even now, were used as softeners in water-based paintings. In general, these compounds are dangerous owing to their carcinogenicity and reproductive effects. Phthalates are not chemically but only physically bound to the matrices, hence, they may be leached into the environment and are ubiquitously found in environmental matrices. Considering that, construction is one of most important fields in Europe, and probably worldwide, with respect to its economic, technological and environmental impact. In the present work the phthalate esters content of several mural paintings was evaluated by gas chromatographymass spectrometry (GC-MS). Because, this issue is especially important to ensure proper security measurements during processes that could involve particulate inhalation, the total concentrations of 15 compounds in the analyzed mural paintings, ranged from 0.8 to $236 \mathrm{mg} / \mathrm{Kg}$ d.w. with an average of $39.4 \mathrm{mg} / \mathrm{Kg} \mathrm{d}$.w. The highest concentration was found in a mural painting sampled in an apartment built about 50 years ago, though, building age was not significantly correlated with the levels of total and single PAEs. Among the monitored phthalates, only four (bis(2-ethylhexyl) phthalate, diisobutyl phthalate, Di-n-butyl phthalate and diethyl phthalate) were detected in appreciable quantities. Benzyl butyl phthalate was relevant only for one sample and, at trace levels, only for two samples. In all tested mural paintings, except two samples, predominates the bis(2-ethylhexyl) phthalate (DEHP) (from 30 to $100 \%$ of total). In general, occasionally, dinonyl phthalate (DNP) was used as an alternative to DEHP, however, in our case, its occurrence was not found. Diisobutyl phthalate (DiBP) was detected in seven samples and ranged from 0.17 to $13.2 \mathrm{mg} / \mathrm{Kg}$ d.w.
\end{abstract}

(C) 2013 Elsevier B.V. All rights reserved.

\section{Introduction}

Indoor environments can be a sources and/or a repository of many kinds of pollutants $[1,2]$ and it is necessary to evaluate their indoor sources, concentrations and distributions in order to assess human exposure to them, especially for children, elderly and sick people, because of their behavioral factors and longer indoor residence time [3].

The hazardous air pollutants are defined by the United State Environmental Protection Agency (EPA), among which there are polycyclic aromatic hydrocarbons (PAHs), polychlorinated biphenyls (PCBs), heavy metals (lead, chrome compounds etc.) usually deposited on surfaces of buildings located in anthropized areas [4]. Also, if a renovation or restore effort is planned for a property, construction workers and building occupants may need to be protected from hazardous substances. Most studies have focused on heavy metals, volatile organic compounds (VOCs), pesticides and less attention has been paid to potential health risks of exposure to persistent and semi-volatile endocrine-disrupting chemicals (EDCs) such as phthalic acid esters, generally called phthalates (PAEs) in the indoor environment [5]. Numerous household products, building materials and pest control

\footnotetext{
* Corresponding author. Tel.: + 3909123897968.

E-mail address: santino.orecchio@unipa.it (S. Orecchio).
}

activities are known as major sources of endocrine disruptor chemicals (EDCs). Traditionally, food consumption has been considered a primary route of exposure to contaminants like those measured in the present study. However, it is becoming clear that exposure through ingestion and/or inhalation of indoor dust may be comparable to corresponding food consumption especially for younger children [6]. It has been suggested that indoor dust is highly contaminated by phthalates and many other hazardous chemicals and thus indoor residential exposure may be a greater contributor to overall exposure than diet [7].

Phthalate esters for decades, and probably even now, were used as softeners in water-based synthetic paintings. Dinbutylphthalate (DBP) and Bis(2-ethylhexyl) phthalate (DEHP) are the most employed. Softeners are released from the painted surface for a long time after it has been applied [8]. Surfaces and structures, such as house walls painted with phthalates based paintings, can be a concern to construction workers engaged in demolition, restore and paint removal activities if they are not protected from hazardous dust inhalation.

Phthalates with higher molecular weights, such as bis(2-ethylhexyl) phthalate, are largely used as additives softeners and plasticizers, while those with lower molecular weights (diethyl, di-n-butyl and dimethyl phthalate) are components of industrial solvents, adhesive, wax, ink, pharmaceutical products, insecticide materials, and cosmetic [9]. DEHP was found in medical disposals devices and in a number of medicine 
coatings. Some compounds are contained in cleaning solutions for contact lenses [10] and in food packaging films [11].

Phthalates are not chemically but only physically bound to the matrices, hence, they may be leached into the environment and are ubiquitously found in dust, air, water, soils, and sediments [2,12-15].

Unfortunately, the phthalate concentrations that can be mobilized from surfaces are not usually determined. This issue is especially important to ensure proper security measurements during processes that could involve particulate inhalation. Construction is one of most important fields in Europe, and probably worldwide, with respect to its economic, technological, and environmental impact. In this context, important issues arise: construction, restore and demolition hazardous materials, in particular dusts that can be inhaled. Construction, renovation and repair dusts are generated in these processes, and during transporting, storing and handling construction materials. This may also be verified when certain construction processes are undertaken. Some works regarding other pollutants in construction materials are concentrated on PCBs in joint sealing materials and how this class of chemicals have spread into the environment and surrounding materials [16]. In the last years, Unites States Environmental Protection Agency (EPA) [17] sponsored a program aimed at reducing lead-based paint emissions in the environment from use, demolition and renovation of buildings but no actions has been taken about other dangerous substances such as phthalate esters. Protracted residence times and work on building matrices containing dangerous substances in the indoor environment increase possibility of exposure to contaminants by 1000 -fold compared to outdoor exposures [18]. Levels of phthalates in indoor air and dust are often higher than outdoor levels $[19,20]$.

Among the hazardous pollutants [20], phthalate esters are dangerous owing to their carcinogenicity and reproductive effects [21]. Phthalates, generally, are colorless and odourless liquids having high boiling points $\left(228-380{ }^{\circ} \mathrm{C}\right)$, low volatility, insolubility in water and predominantly fat solubility. Excluding the dimethyl phthalate (DMP), which belong to the group of VOCs, PAEs are classified as semi-volatile organic compounds. There are no naturally occurring PAEs, therefore all phthalates found in environmental matrices can be accredited only to man-made materials. PAEs are emitted into the atmosphere as particulates and gasses [22]. Weschler [22] argues that, the less volatile PAEs are more likely to be deposited on the indoor surfaces bound to particles in wet and dry deposition. In particular, for compounds of intermediate vapor pressure, a temperature-dependent gas/particle portioning of PAEs will occur, and thus, they are subject to both wet and dry deposition in gaseous and particle-bound form. The transport, residence time, fate, and reactions of PAEs in atmosphere are widely controlled by their gas-particle partitioning [23]. About indoor pollution, indoor environments increase the lifetime of substances adsorbed to the dust by minimizing or eliminating the natural decomposition processes catalyzed by natural light and rain [24].

Moreover, numerous household products, building materials, and pest control activities are known as major sources of endocrinedisrupting chemicals. Evidence for the adverse effects of this class of substances on human health is mounting $[5,7,19,22,21,25-27]$. Thus, there is the need to acquire more information about the occurrence of EDCs in indoor matrices and the associated potential risk.

Workers manufacturing materials containing phthalates are greatly exposed and have shown to have urinary metabolite concentrations that often exceed those at the 95th percentile of the common population [28]. Such as reported PAEs are not very volatile, but they readily form aerosols that may be inhaled in particular during work with high temperature processes [29]. In addition, dermal exposures could potentially play a role in low temperature operations; on the other hand, due to their chemical characteristics (lipophilicity), dermal phthalate absorption is assumed to below or negligible. Several authors [29-31] claim that this theory might be not true because among phthalates exposed workers performing low temperature processes was found the presence of urinary PAEs metabolites. Gaudin [30] founds elevated urinary 5cx-MEPP metabolite concentrations (median $107.5 \mathrm{~g} / \mathrm{L}$ ) among workers preparing a DEHP-containing material at room temperature. In a study [31], workers refinishing phthalate-containing sealants at room temperatures had 20 times higher metabolite concentrations than the control group.

The principal aim of this study was to determine the concentrations and distribution of 15 PAEs presents in the surface layer of walls (mural paintings) of some buildings. In order, to get a better insight in environmental levels and distribution of these compounds, reliable analytical methods are required capable of measuring a large range of PAEs at low concentrations. There are some studies on the concentrations of PAEs in different matrices $[2,7,10]$ but information about the occurrence and distribution of PAEs in mural paintings materials are absent.

One of the analytical difficulties that may occur with building materials is the complexity of matrices and differences in their compositions. Therefore, it is need check the validity of the analytical method using the material to be analyzed. In this paper we report an analytical method for 15 PAEs which adopts and improves previous knowledge and affords better results on the concentration levels and the distribution of phthalates in wall paintings.

GC/MS was used to quantify PAEs in samples taken from wall surface of eight building located in Palermo, in an attempt to demonstrate the presence and the hazards of substances, often not even known to the specific operators and managers.

\section{Experimental}

\subsection{Study area}

The buildings taken in consideration in this study are located in Palermo area (Italy). Palermo is a densely populated city (about 850,000 inhabitants). It is characterized by conspicuous air pollution $[1,32-37]$. The town is situated on the north-western coast of the island along the wide bay Piana di Palermo and is overlooked by Mt. Pellegrino (600 $\mathrm{m}$ above sea level). Palermo is a typically European town in building style and is generally built in stone (tuff), clay bricks and concrete.

In order to determine a possible pattern in usage of PAEs in the Palermo area, sampling was conducted in different parts of the town, in different types of buildings of different ages (Table 1 ). The samples were taken, during 2012 from the surface of the walls from eight buildings and were collected by scraping off the layers or removing fragments; care was taken to ensure that the samples were representative of the single room. From each surface, a total of 5 samples were collected. About $25 \mathrm{~g}$ of the material were placed in glass containers. The samples were refrigerated $\left(4^{\circ} \mathrm{C}\right)$, avoiding the exposure to light, and taken to the laboratory where they were frozen $\left(-20^{\circ} \mathrm{C}\right)$ until the analysis was performed. About $2 \mathrm{~g}$ of homogenized samples of mural painting were dried at $105{ }^{\circ} \mathrm{C}$ for overnight. The water content was determined by weight loss and was utilized to correlate all the results with dry weight. Before each analysis the samples were finely pulverized in a mortar.

Table 1

Descriptive profile of sampling station.

\begin{tabular}{lll}
\hline $\mathrm{n}^{\circ}$ & Characteristic of station & $\begin{array}{l}\text { Age of } \\
\text { building }\end{array}$ \\
\hline Mur 1 & Stair of a building build around 1990. & 23 \\
Mur 2 & Bedroom of an apartment on the first floor & 25 \\
Mur 3 & Stair of the previous station & 25 \\
Mur 4 & Living room of house dating from 1950 to & 63 \\
& 1 floor renovated 13 years ago. & \\
Mur 5 & Kitchen of an apartment on the top floor. & 15 \\
Mur 6 & Garage & 43 \\
Mur 7 & Kitchen & 30 \\
Mur 8 & Kitchen & 5 \\
\hline
\end{tabular}




\subsection{Chemical analyses}

Mural painting samples were analyzed for 15 PAEs (Table 2). An aliquot ( $1 \mathrm{~g}$ ) of material was extracted (3 times) with hexane using an ultrasound bath for $20 \mathrm{~min}$. Before extraction, surrogate standard (Di-n-hexyl-phthalate- $\mathrm{d}_{4}$ ) was added to all samples for the evaluation of the method performance (yields). The extracts were filtered through a Pasteur pipette filled with anhydrous $\mathrm{Na}_{2} \mathrm{SO}_{4}$, previously rinsed with hexane, and concentrated in a rotary evaporator at $\mathrm{T}=50{ }^{\circ} \mathrm{C}$. The final volume was around $1 \mathrm{~mL}$. The last stage in the procedure involved drying the PAEs containing solution under a weak inert gas flow at room temperature. The dry residue was dissolved in $1 \mathrm{~mL}$ of solution containing perdeuterated internal standards (Bis(2-ethylhexyl)phthalate- $\mathrm{d}_{4}$ ) in cyclohexane. Target compounds were analyzed with Shimadzu mod. GC-17A gas chromatograph equipped with a SPB5 (30 m 0.25 i.d., $0.5 \mu \mathrm{m}$ ) (5\% diphenyl 95\% dimethyl siloxane) phase fused-silica capillary column from Supelco (Milano, Italy) and a Shimadzu, quadrupole detector mod. GCMSQP5000. The mass spectrometer was operated in electron impact (70 eV) and selected ion monitoring (SIM) mode. GC oven temperature for PAEs started at $60{ }^{\circ} \mathrm{C}(2 \mathrm{~min}$. $)$ and ramped to $325^{\circ} \mathrm{C}$ at $14.5{ }^{\circ} \mathrm{C} / \mathrm{min}$ and maintained for $30 \mathrm{~min}$.

Injection of $1 \mu \mathrm{L}$ sample was performed manually. The instrument was equipped with a split/splittless injector with glass wool injection port liner and splittless time of $2 \mathrm{~min}$. Total flow $21 \mathrm{ml} / \mathrm{min}$ was used. The carrier gas was helium (flow rate $1.4 \mathrm{ml} / \mathrm{min}$ ). In several cases, to measure phthalates, sample extracts were diluted prior to GC analyses.

\subsection{Quality assurance}

The detection limits (LOD) was estimated as $3 \sigma$ (three times the background noise) (IUPAC criterion) and like reported in previous papers $[2,4,36,37]$ was similar for all analyzed compounds (less than $0.3 \mu \mathrm{g} / \mathrm{Kg}$ for all compounds). Quantification limit (LOQ), (less than $1 \mu \mathrm{g} / \mathrm{Kg}$ for all compounds) was estimated as $10 \sigma$ (ten times the background noise) (IUPAC criterion). LOD and LOQ were estimated in single ion monitoring (SIM) mode [2,33,34,36,38]. Blank concentrations were not subtracted from sample concentrations because the levels in samples were higher than blank levels by several orders of magnitude.

The procedure was checked for recovery efficiencies by analyzing uncontaminated samples, preventively obtained by extraction of three

\section{Table 2}

List of the PAEs and abbreviations, the deuterated internal (underlined) and surrogate (italic) standards employed, the quantification and confirmation ions for SIM GC/MS mode.

\begin{tabular}{llll}
\hline Compound & Abbr. & $\mathrm{N}^{\circ}$ CAS & $\begin{array}{l}\text { Quantification and } \\
\text { confirmation ions } \\
(\mathrm{m} / \mathrm{z})\end{array}$ \\
\hline Dimethyl phthalate & DMP & $131-11-3$ & $163-194$ \\
Diethyl phthalate & DEP & $84-66-2$ & $121-149$ \\
Diisobutyl phthalate & DiBP & $84-69-5$ & $149-167$ \\
Di-n-butyl phthalate & DBP & $84-74-2$ & $149-150$ \\
Bis(2-methoxyethyl) phthalate & DMEP & $117-82-8$ & $59-149$ \\
Bis(4-methyl-2-pentyl) phthalate & BMPP & $146-50-9$ & $121-149$ \\
Dinonyl phthalate & DNP & $86-76-4$ & $57-71$ \\
Bis(2-ethoxyethyl) phthalate & DEEP & $605-54-9$ & $45-72$ \\
Di pentyl phthalate & DPP & $131-18-0$ & $149-167$ \\
Dihexyl phthalate & DHxP & $84-75-3$ & $76-104$ \\
Bis(2-n-butoxyethyl) phthalate & DBEP & $117-83-9$ & $57-149$ \\
Bis(2-ethylhexyl) phthalate & DEHP & $117-81-7$ & $113-149$ \\
Di-ciclohexyl phthalate & DCHP & $84-61-7$ & $83-149$ \\
Di-n-octil phthalate & DOP & $117-84-0$ & $149-150$ \\
Benzyl butyl phthalate & BBP & $85-68-7$ & $91-149$ \\
Diethyl phthalate-d & & 153 \\
\hline Bis(2-ethylhexyl)phthalate- $\mathrm{d}_{4}$ & $\overline{\text { BEPd }}_{\mathbf{4}}$ & & 153 \\
\hline Di-n-hexyl-phthalate- $d 4$ & $\overline{\text { DHXP d }}_{\mathbf{4}}$ & & 153 \\
\hline
\end{tabular}

samples of mural painting collected in two stations area for $2 \mathrm{~h}$ (three times) with hexane and spiked with a known quantity of PAEs standards. The average recoveries ranged from $79 \%$ to $102 \%$. The relative standard deviations on the PAEs measurements of recovery are less than $12 \%$. Relative percent differences for triplicate samples were less than $10 \%$.

\section{Results and discussion}

The total concentrations (the average of three analyses) of 15 compounds, expressed as the sum of the concentrations, ¿PAEs, in the analyzed mural painting, ranged from 0.8 to $236 \mathrm{mg} / \mathrm{Kg}$ d.w. with an average of $39.4 \mathrm{mg} / \mathrm{Kg} \mathrm{d.w.} \mathrm{(Fig.} \mathrm{1)} \mathrm{(Table} \mathrm{3).} \mathrm{The} \mathrm{highest} \mathrm{concentra-}$ tions were found in a wall paint (mural 4) sampled in a living room of an apartment built about 50 years ago.

The wide range of phthalates contents (relative standard deviation on total phthalates was 203\%) found in the analyzed samples indicates heterogeneous composition of the wall paintings. In Table 2 we report the concentrations of each individual PAE in the analyzed samples, while in Fig. 2 are shown the distributions (\%) of single compounds. Among the 15 monitored phthalates only four (DEHP, DiBP, DBP and $\mathrm{DEP}$ ) were detected in appreciable quantities. BBP was relevant only for one sample and at trace levels only in two samples.

In all tested samples, except mur 1 and mur 8, predominates the DEHP (from 30 to $100 \%$ of total phthalates) that is in the range from 0.6 to $236 \mathrm{mg} / \mathrm{Kg} \mathrm{d.w}$. In general, occasionally, DiNP was used as an alternative to DEHP, however, in our case, its occurrence was not found.

Human absorption to DEHP can occur, in our case, via the dermal and inhalation routes of exposure. DEHP is not classifiable as to carcinogenicity in humans but has been described as carcinogenic in mice and rats by the International Agency for Research on Cancer [27]. Moreover DEHP is a recognized testicular toxicant, altering the normal functions of Sertoli and Leydig cells by affecting spermatogenesis and testosterone production in rats [5], in fact, phthalates are classified in the EU as category 2 substances to reproduction and as $1 \mathrm{~B}$ in the Globally Harmonized System of Classification System and Labeling of Chemicals (GHS). Other studies [38] argue that high doses of DEHP induced liver and kidney damage, testicular toxicity, and endocrine disorders in androgen production. In humans, the reported health effects of DEHP are altered semen quality, reproductive and developmental effects, and endocrine disruption, which have recently caused much public concern [39]. Inhaling DEHP aerosols in combination with allergens may lead to allergic lung inflammation and increased allergic sensitization in laboratory animals [40] and may be associated with asthma and allergies in children [41]. Several researchers claim that skin contact with matrices contaminated with a wide variety of phthalates might increase possible dermal absorption [42].

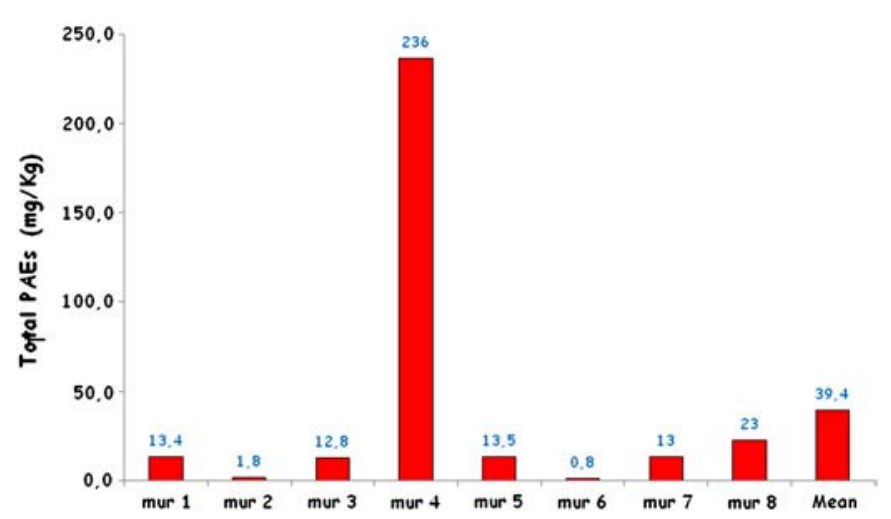

Fig. 1. Total PAEs (in $\mathrm{mg} / \mathrm{kg}$ ) (average of three analysis) concentrations in mural painting samples. 
Table 3

Single PAEs (in $\mathrm{mg} / \mathrm{kg}$ ) (average of three analysis) concentrations in mural painting samples.

\begin{tabular}{|c|c|c|c|c|c|c|c|c|c|c|c|c|c|c|c|}
\hline Station & DEP & DMP & DiBP & DBP & DMEP & BMPP & DNP & DEEP & DPP & DHxP & BBP & DBEP & DEHP & DCHP & DOP \\
\hline mur 1 & 1.1 & 0.008 & 6.15 & 0.60 & $<0.0003$ & $<0.0003$ & $<0.0003$ & 0.017 & $<0.0003$ & 0.035 & 1.5 & $<0.0003$ & 4.0 & $<0.0003$ & $<0.0003$ \\
\hline mur 2 & 0.046 & $<0.0003$ & 0.34 & 0.070 & $<0.0003$ & $<0.0003$ & $<0.0003$ & $<0.0003$ & $<0.0003$ & 0.0016 & 0.043 & $<0.0003$ & 1.3 & $<0.0003$ & 0.016 \\
\hline mur 3 & 0.027 & 0.0008 & 0.95 & 0.064 & $<0.0003$ & $<0.0003$ & $<0.0003$ & 0.0045 & $<0.0003$ & 0.0039 & 0.25 & $<0.0003$ & 11 & $<0.0003$ & 0.18 \\
\hline mur 4 & 0.013 & 0.0004 & 0.29 & 0.14 & $<0.0003$ & 0.0051 & $<0.0003$ & $<0.0003$ & $<0.0003$ & 0.0026 & 0.054 & $<0.0003$ & 236 & $<0.0003$ & 0.14 \\
\hline mur 5 & 0.034 & $<0.0003$ & 2.1 & 0.29 & $<0.0003$ & $<0.0003$ & $<0.0003$ & $<0.0003$ & $<0.0003$ & 0.045 & $<0.0003$ & $<0.0003$ & 11 & $<0.0003$ & $<0.0003$ \\
\hline mur 6 & 0.021 & $<0.0003$ & 0.17 & 0.037 & $<0.0003$ & $<0.0003$ & $<0.0003$ & $<0.0003$ & $<0.0003$ & 0.0029 & $<0.0003$ & $<0.0003$ & 0.55 & $<0.0003$ & $<0.0003$ \\
\hline mur 7 & 0.034 & $<0.0003$ & 2.1 & 0.29 & $<0.0003$ & $<0.0003$ & $<0.0003$ & $<0.0003$ & $<0.0003$ & 0.045 & $<0.0003$ & $<0.0003$ & 11 & $<0.0003$ & $<0.0003$ \\
\hline mur 8 & 0.31 & $<0.0003$ & 13.2 & 1.8 & $<0.0003$ & $<0.0003$ & $<0.0003$ & 0.027 & 0.030 & 0.13 & 0.039 & $<0.0003$ & 7.2 & $<0.0003$ & $<0.0003$ \\
\hline
\end{tabular}

Diisobutyl phthalate (DiBP) was detected in seven samples and ranged from 0.17 to $13.2 \mathrm{mg} / \mathrm{Kg}$ d.w., measured, respectively, in mural 6 and in mural 8. Some authors affirm that exposure to DiBP during growth is related with the phthalate syndrome, which comprises principally endpoints associated with the decreased testicular testosterone production, decreased anogenital distance, hypospadias, reduced sperm quality and decreased fertility [43].

Some of these disorders along with other health harmful effects have also been observed in other epidemiologic studies [44]. According to our knowledge, there are not specific studies that examines the relationship between DiBP metabolites levels and alteration of human reproductive system.

$\mathrm{DEP}$, at appreciable concentrations was detected in only three samples in the range from $0.013 \mathrm{mg} / \mathrm{Kg}$ d.w. (mural 4) to $1.1 \mathrm{mg} / \mathrm{Kg}$ d.w. (mural 1). The data suggest that, in these three samples, DEP was not negligible compared to concentrations of the other phthalates and was intentionally added to products.

Because diethyl phthalate is not a part of the matrix which makes up the painting, it can be released fairly easily from these products. DEP was shown to be slightly irritating when applied continually to the skin. In rats treated with DEP for 2 years, a mild, apparently adaptive skin acanthosis was establish [45]. Using marked DEP $\left({ }^{14} \mathrm{C}\right)$, significant percutaneous absorption has been reported for an application of the chemical to the clipped skin of male rats, resulted in a cumulative excretion of $50 \%$ in a week, while $34 \%$ of the dose remained in the area of application [46]. By tests on several human volunteers, DEP has not been reported to be a dermal sensibilizer, while positive results have been reported in some of the studies with patients [46]. Once it enters the organism, DEP breaks down into other products, some of which are harmful. Diethyl phthalate and its breakdown products will leave the organism mostly in the urine within about 2 days. Only small amounts of the DEP or its breakdown products remain in the body tissues with the greatest accumulation in the kidney and liver [46].

No inhalation minimal risk levels were resulting for DEP [47]. The only known inhalation study in either humans or animals was

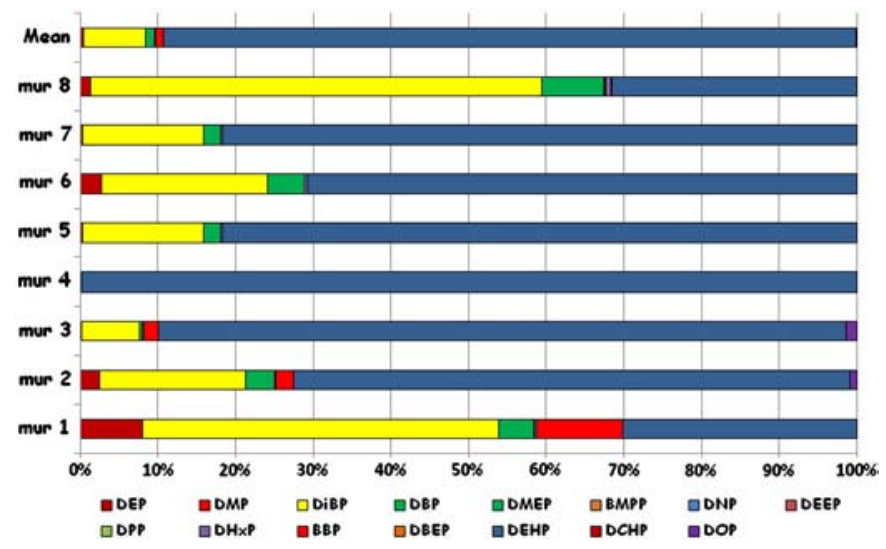

Fig. 2. Distributions (\%) of single PAE. conducted in an occupational group exposed to vapors from solvents and welding gas of cellulose acetate, which contained 30\% diethyl phthalate [48]. This study was limited because of the small group size, co-exposure to other substances, inappropriate control data, and little exposure information. DEP is also known to be a suspect carcinogen.

Our results, in good agreement to other researchers [9], suggest that, excluding few cases, in the samples, the other analyzed phthalates (Table 2) were present as impurities and were not intentionally added to the paintings.

Building age was not significantly correlated with the levels of total and single PAEs.

\section{Conclusion}

The literature claims $[9,10,24,42]$ that there is a wide variety of consumer products that contain phthalate, but to our knowledge, no article speaks of the presence of the DEP in wall paintings, and in products for the construction industry.

This study shows the analytical method development to determinate PAEs in mural painting samples. Under the conditions used, the percentage recoveries were in the range accepted from IUPAC criterions; in every case they are greater than $80 \%$ and in most of the cases near $100 \%$. The reproducibility is also satisfactory (relative standard deviation $=10 \%$.

Also, the results of this research offer a scientific basis for risk analysis, especially for restorers, caused by hazardous PAEs deriving by the building materials.

The present study demonstrates that the indoor environments are significantly contaminated by EDCs and their levels are high enough to be possibly linked to some adverse health effects.

As a preliminary study, mural painting samples were collected from only eight different buildings. Systematic investigation is required to find possible links between exposure to EDCs indoors and adverse health effects.

The results of the present study suggest that aeration of indoor air and the use of appropriate personal protective equipments, during the execution of renovation or restoration may be wanted in an attempt to reduce exposure to EDCs. Workers should also be aware of possible risks of exposure to EDCs, and in other cases to polycyclic aromatic hydrocarbons [4,49], for example, when they demolish, restore or renovate. Those data should be helpful for structuring the phthalates exposure profile and recommending local exhaust systems and personal protection equipment for construction workers.

Our findings suggest that, in European dwellings, attention should be paid not only to PVC floor materials and paper wall, as sources of PAEs but other matrices such as wall paintings should be evaluated as sources of substances that damage the hormonal system.

Also, because PAEs are not chemically, but only physically bound to the building materials, they, may be leached by water percolating through landfills [50].

However, the laws regulating phthalate use only apply to food containers, medical devices, and toys that could be placed in a child's mouth. Regulation of phthalate use in building materials and interior materials should also be considered. 


\section{Acknowledgments}

This study was made possible by the financial support of Palermo University that has funded the author (Grants ex 60\% 2007).

\section{References}

[1] M.R. Mannino, S. Orecchio, Polycyclic aromatic hydrocarbons (PAHs) in indoor dust matter of Palermo (Italy) area: extraction, GC-MS analysis, distribution and sources, Atmos. Environ. 42 (2008) 1801-1817.

[2] S. Orecchio, R. Indelicato, S. Barreca, The distribution of phthalate esters in indoor dust of Palermo (Italy), Environ. Geochem. Health 35 (2013) 613-624.

[3] J. Robinson, W.C. Nelson, National Human Activity Pattern Survey Data Base, United States Environmental Protection Agency, Research Triangle Park, NC, 1995.

[4] S. Orecchio, Analytical method, pattern and sources of polycyclic aromatic hydrocarbons (PAHs) in the stone of the Temples of Agrigento (Italy), J. Hazard. Mater. 176 (2010) 339-347.

[5] G.W. Wolfe, K.A. Layton, Multigeneration reproduction toxicity study in rats diethylhexylphthalate: multigenerational reproductive assessment by continuous breeding when administered to Sprague-Dawley rats in the diet, The Immune Research Corporation, Gaithersburg, Mary-land, 2003. (TRC Study no. 7244-200).

[6] B.H. Wilford, M. Shoeib, T. Harner, T. Zhu, K.C. Jones, Polybrominated dipheny ethers in indoor dust in Ottawa, Canada: implications for sources and exposure, Environ. Sci. Technol. 39 (2005) 7027-7035.

[7] M. Lorber, H.M. Koch, Development and application of simple pharmacokinetic models to study human exposure to di-n-butyl phthalate (DnBP) and diisobutyl phthalate (DiBP), Environ. Int. 59 (2013) 469-477.

[8] B. Berge, The ecology of building materials, 2nd edition Elsevier, USA, 2009

[9] D. Koniecki, R. Wang, R.P. Moody, J. Zhu, Phthalates in cosmetic and personal care products: concentrations and possible dermal exposure, Environ. Res. 111 (2011) 329-336.

[10] C. Perez-Feas, M.C. Barciela-Alonso, P. Bermejo-Barrera, Presence of phthalates in contact lens and cleaning solutions, Microchem. J. 99 (2001) 108-113.

[11] M. Bonini, E. Errani, G. Zerbinati, E. Ferri, S. Girotti, Extraction and gas chromatographic evaluation of plasticizers content in food packaging films, Microchem. J. 90 (2008) 9031-9036.

[12] P. Wang, S.L. Wang, C.Q. Fan, Atmospheric distribution of particulate- and gas-phase phthalic esters (PAEs) in a metropolitan city, Nanjing, East China, Chemosphere 72 (2008) 1567-1572

[13] F. Wang, X.H. Xia, Y.J. Sha, Distribution of phthalic acid esters in Wuhan section of the Yangtze River, China, Hazard. Mater. 154 (2008) 317-324.

[14] X. Xia, L. Yang, Q. Bu, R. Liu, Levels, distribution, and health risk of phthalate esters in urban soils of Beijing, China, J. Environ. Qual. 40 (2011) 1643-1651.

[15] F. Zeng, K. Cui, Z. Xie, L. Wu, D. Luo, L. Chen, Distribution of phthalate esters in urban soils of subtropical city, Guangzhou, China, Hazard. Mater. 164 (2009) 1171-1178.

[16] S. Russel, H. Parker, A. Parker, Frontiers in Geochemistry, Willey Blackwell, USA, 2011

[17] Unites States Environmental Protection Agency, An Introduction to Indoor Air Quality (IAQ), http://www2.epa.gov/lead/lead-outreach-partnerships-and-grants.

[18] R.M. Smith, Supercritical fluid chromatography, Anal. Chem. 60 (24) (1988) 1394A

[19] B. Kolarik, C.G. Bornehag, K. Naydenov, J. Sundell, P. Stavova, O.F. Nielsen, The concentrations of phthalates in settled dust in Bulgarian homes in relation to building characteristic and cleaning habits in the family, Atmos. Environ. 42 (2008) 8553.

[20] R.M. Maerteens, J. Bailey, P.A. White, The mutagenic hazards of settled house dust: a review, Mutat. Res. Rev. Mutat. Res. 567 (2004) 401-425(8559).

[21] R. Kavlock, K. Boekelheide, R. Chapin, M. Cunningham, E. Faustman, P. Foster, Center for the evaluation of risks to human reproduction: phthalates expert panel report on the reproductive and developmental toxicity of butyl benzylphthalate, Reprod. Toxicol. 16 (2002) 453-653.

[22] C.J. Weschler, T. Salthammer, H. Fromme, Partitioning of phthalates among the gas phase, airborne particles and settled dust in indoor environment, Atmos. Environ 42 (2008) 1449-1460.

[23] M. Wormuth, M. Scheringer, M. Vollenweider, K. Hungerbuhler, What are the sources of exposure to eight frequently used phthalic acid esters in Europeans? Risk Anal. 26 (2006) 803-824.

[24] J.V. Cizdziel, V.F. Hodge, Attics as archives for house infiltrating pollutants: trace elements and pesticides in attic dust and soil from southern Nevada and Utah, Microchem. J. 64 (2000) 85-92.

[25] Y. Grosse, R. Baan, B. Secretan-Lauby, F. El Ghossassi, V. Bouvard, L. Benbrahim-Talla, N. Guha, F. Islami, L. Galichet, K. Straif, WHO International Agency for Research on Cancer Monograph Working Group, Carcinogenicity of chemicals in industrial and consumer products, food contaminants, and flavourings, and water chlorination byproducts, Lancet Oncol. 12 (2011) 328-329.
[26] D.B. Martinez-Arguelles, M. Culty, B.R. Zirkin, V. Papadopoulos, In utero exposure to di-(2-ethylhexyl) phthalate decreases mineral ocorticoid receptor expression in the adult testis, Endocrinology 150 (2009) 5575-5585.

[27] T. Nakajima, NancyB. Hopf, A. Paul Schulte, Di(2-ethylhexyl) phthalate (DEHP), Identification of Research Needs to Resolve the Carcinogenicity of High-priority IARC Carcinogens, Views and Expert Opinions of an IARC/NORA Expert Group Meeting, Lyon, France, 30 June-2 July 2009, IARC Technical Publication, No. 42, IARC, Lyon, 2010, pp. 183-196, (http://monographs.iarc.fr/ENG/Publications/techrep42/ TR42-18.pdf).

[28] NRC (National Research Council), Phthalates and cumulative risk assessment; the task ahead, National Academies Press (U.S.), Washington, DC, 2008.

[29] N.B. Hopf, A. Berthet, D. Vernez, E. Langard, P. Spring, R. Gaudin, Skin permeation and Metabolism of di(2-ethylhexyl) phthalate (DEHP), Toxicol. Lett. 224 (2014) 47-53.

[30] R. Gaudin, P. Marsan, S. Ndaw, A. Robert, P. Ducos, Biological monitoring of exposure to di(2-ethylhexyl) phthalate in six French factories: a field study, Int. Arch. Occup. Environ. Health 84 (2011) 523-531.

[31] H.M. Koch, K.L.Y. Christensen, V. Harth, M. Lorber, T. Bruening, Di-n-butyl Phthalate (DnBP) and diisobutyl phthalate (DiBP) metabolism in a human volunteer after Single oral doses, Arch. Toxicol. 86 (2012) 1829-1839.

[32] S. Orecchio, D. Amorello, Platinum levels in urban soils from Palermo (Italy); analytical method using voltammetry, Microchem. J. 99 (2011) 283-288.

[33] S. Orecchio, PAHs associated with leaves of Quercus ilex L.: extraction, GC-MS analysis, distribution and sources. Assessment of air quality in the Palermo (Italy) area, Atmos. Environ. 41 (2007) 8669-8680.

[34] A. Gianguzza, L. Culotta, S. Orecchio, Absorption of polycyclic aromatic hydrocarbons by pinus bark: analytical method and use for environmental pollution monitoring in the Palermo area (Sicily, Italy), Environ. Res. 107 (2008) 371-379.

[35] S. Orecchio, D. Amorello, Platinum and rhodium associated with the leaves of Nerium oleander L.; analytical method using voltammetry; assessment of air quality in the Palermo (Italy) area, J. Hazard. Mater. 174 (2010) 720-727.

[36] S. Orecchio, Contamination from polycyclic aromatic hydrocarbons (PAHs) in the soil of a botanical garden localized next to a former manufacturing gas plant in Palermo (Italy), J. Hazard. Mater. 180 (2010) 590-601.

[37] A. Macaluso, R. Maria, S. Orecchio, The use of leaves of Olea europaea L. as passive samplers for polycyclic aromatic hydrocarbons. Assessment of the quality of the air in Palermo, Annali di Chimica 90 (2000) 83-90.

[38] S. Barreca, S. Orecchio, A. Pace, Photochemical sample treatment for extracts clean up in PCB analysis from sediments, Talanta 103 (2013) 349-354.

[39] J. Mendiola, J.D. Meeker, N. Jørgensen, A.M. Andersson, F. Liu, A.M. Calafat, J.B. Redmon, E.Z. Drobnis, A.E. Sparks, C. Wang, R. Hauser, S.H. Swan, Urinary concentrations of di(2-ethylhexyl) phthalate metabolites and serum reproductive hormones: pooled analysis of fertile and infertile men, J. Androl. 33 (2012) 488-498.

[40] S.T. Larsen, J.S. Hansen, E.W. Hansen, P.A. Clausen, G.D. Nielsen, Airway inflammation and adjuvant effect after repeated airborne exposures to di-(2-ethylhexyl) phthalate and ovalbumin in BALB/c mice, Toxicology 235 (2007) 119-129.

[41] G. Bornehag, J. Sundell, C.J. Weschler, T. Sigsgaard, B. Lundgren, M. Hasselgren, L. Hägerhed-Engman, The association between asthma and allergic symptoms in children and phthalates in house dust: a nested case-control study, Environ. Health Perspect. 112 (2004) 1393-1397.

[42] M. Romero-Franco, R.U. Hernández-Ramír, A.M. Calafa, M.E. Cebrián, L.L. Needham, S. Teitelbaum, M.S. Wolff, L. López-Carrillo, Personal care product use and urinary levels of phthalate metabolites in Mexican women, Environ. Int. 37 (2011) 867-871.

[43] P.M.D. Foster, R.C. Cattley, E. Mylchrees, Effects of Di-n-butyl phthalate (DBP) on male reproductive development in the rat: implications for human risk assessment, Food Chem. Toxicol. 38 (2000) S97-S99.

[44] J. Jurewicz, W. Hanke, Exposure to phthalates: reproductive out come and children health. A review of epidemiological studies, Int. J. Occup. Med. Environ. Health 24 (2011) 114-141.

[45] V. Sonde, A. D'souza, R. Tarapore, L. Pereira, M.P. Khare, P. Sinkar, S. Krishnan, C.V. Rao, Simultaneous administration of diethylphthalate and ethyl alcohol and its toxicity in male Sprague-Dawley rats, Toxicology 147 (2000) 23-31.

[46] A.M. Api, Toxicological profile of diethyl phthalate: a vehicle for fragrance and cosmetic ingredients, Food Chem. Toxicol. 39 (2001) 97-108.

[47] U.S.Department of Health and Human Services, Public health service agency for toxic substances and disease registry, Toxicological Profile for diethyl phthalatejune 1995. (http://www.atsdr.cdc.gov/toxprofiles/tp73.pdf).

[48] H.F. Beving, S. Petren, O. Vesterberg, Increased isotransferrin ratio and reduced erythrocyte and platelet volumes in blood from thermoplastic industry workers, Ann. Occup. Hyg. 34 (1990) 391-397.

[49] A. Gianguzza, M. Governanti, S. Orecchio, D. Piazzese, Identification of polycyclic aromatic hydrocarbons (PAHS) in the black crusts of Sicilian stone monuments: distribution and sources, Sci. Technol. Cult. Herit. 13 (2004) 53-61.

[50] S.K. Marttinen, R.H. Kettunen, J.A. Rintala, Occurrence and removal of organic pollutants in sewages and landfill leachates, Sci. Total Environ. 301 (2003) 1-12. 